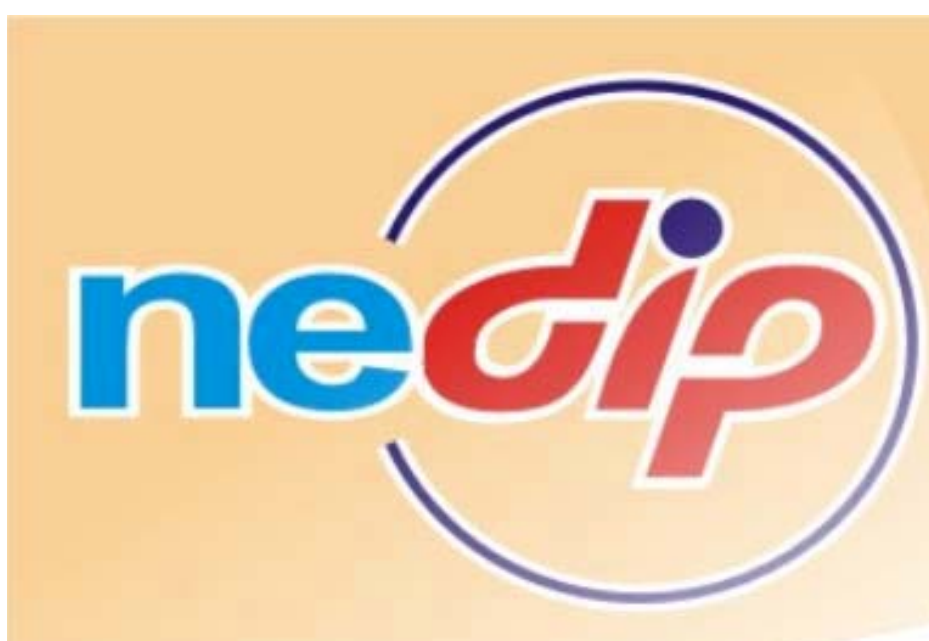

14th ISPE

CE' 2007 - International Conference on Concurrent Engineering

São José dos Campos, Brazil, July $16^{\text {th }}$ to $20^{\text {th }}$

\title{
Guidelines for Reverse Engineering Process Modeling of Technical Systems
}

$\sum 0 \bar{n}$

(11)

POSInEC

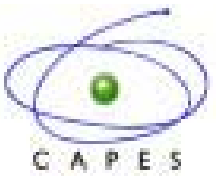

Ivo R. Montanha Junior, M.Eng.

André Ogliari, Dr.Eng.

Nelson Back, Ph.D

núcleo de desenvolvimento integrado de produtos 


\section{Outline}

- Overview

- Literature Review

- Conceptual Design of Technical Systems

- Reverse Engineering for Technical Systems Design

- Product Teardown

- Support Methods Related to Reverse Engineering (RE)

- Technical Visit to a RE Leading Company

- Proposal of the RE Process Modeling

- Guidelines for the RE Model

- Final Considerations 


\section{Overview}




\section{Overview}

- The process of conceptual design is essential to innovation, because it uncouples the design problem from the known solutions by an abstraction process

- In spite of its importance, this process is not effectively carried out by designers

- Standardized functions should guide the designers in the product functional modeling

- Reverse Engineering (RE) is suggested, as a way to model the processes of identifying, purchasing and modeling design information - functions and design principles - in a continuous and systematic way 


\section{Literature Review}




\section{Conception Process of TS}

- In the conceptual design phase, the Technical Systems (TS) conceptions are developed by:

- Functional modeling

- Design principles and

- Product conceptions generation

- The main functional modeling approaches are:

- Functional deployment (Pahl and Beitz)

- Axiom-based synthesis (Tomiyama et al.) and

- The function-means tree (Tjalve)

- The conceptual design demands:

- A significant capacity of abstraction

- An accurate definition of the functions

- RE supports the acquisition of this information 


\section{Reverse Engineering for TS Design}

- RE is "a process of information getting and analysis from existent systems, in order to optimize systems being developed"

- RE seeks to understand how a TS works, not copying technical solutions

- RE methodologies have been suggested to formalize the RE process for TS, considering:

- FAST (Function Analysis System Technique)

- SOP (Subtract and Operate Procedure)

- Force Flow

- Teardown (technical disassembly) 


\section{Product Teardown}

- Teardown is carried out by many companies

- To verify new technologies in the market

- Informally, aiming at the solution of specific problems

- Teardown must:

- Be a formal process of TS disassembling, analyzing each subsystem and component

- Identify the inter-relationships among them, their functions and design principles

- Methodologies of teardown have been suggested:

- Otto and Wood (2001): the practical procedure was emphasized but not the functional modeling

- Abe and Starr (2003): the identification of the TS functions is clear and logical 


\section{Support Methods Related to RE}

- Value Analysis (VA)

- AHP (Analytic Hierarchy Process) soor

- Interface Diagrams

- To identify the connections between the physical components or processes of a TS

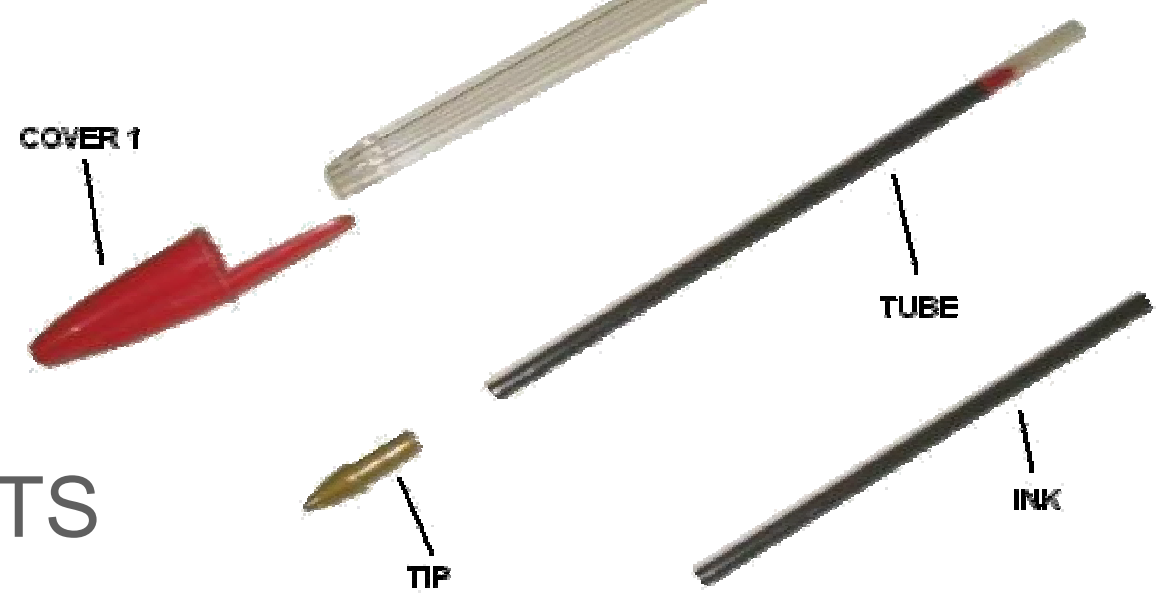

- Assembly analysis methods (DFA approach)

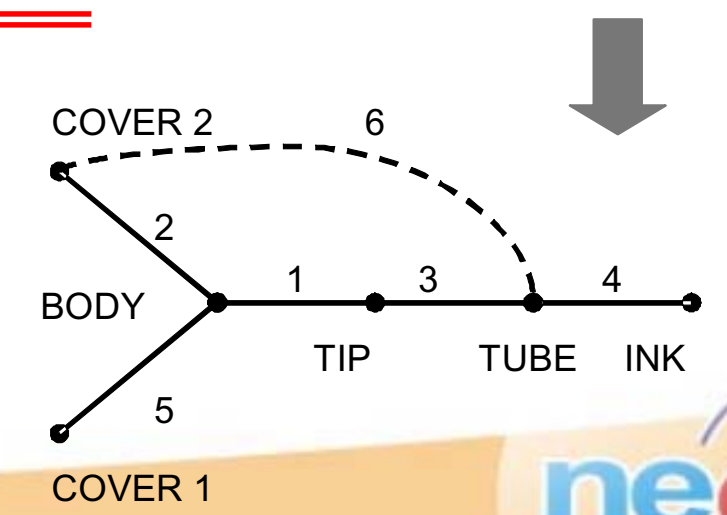




\section{Technical Visit to a Leading RE Company}




\section{Technical Visit to a Leading RE Company}

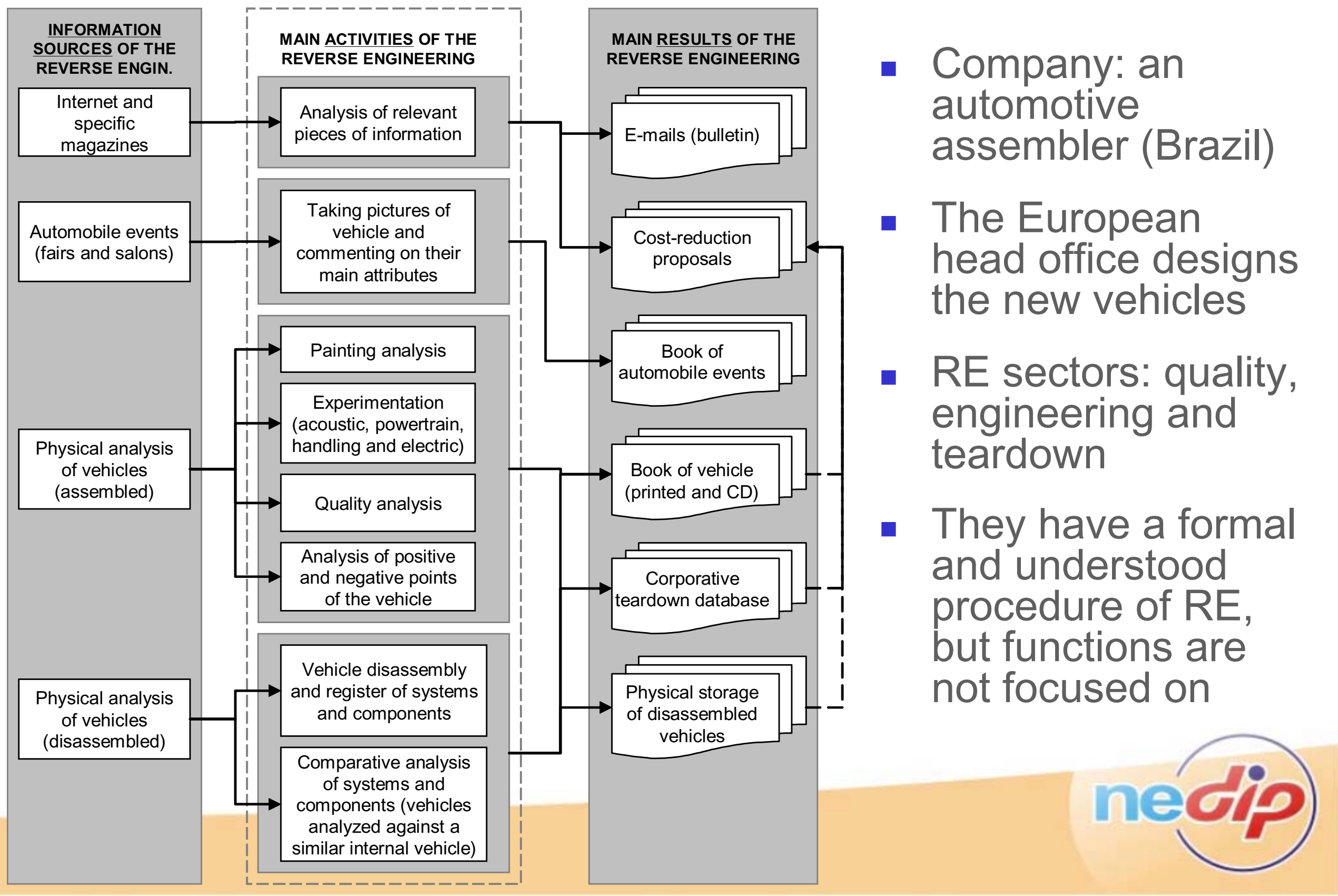




\section{Proposal for the Reverse Engineering Process Modeling}




\section{Proposal for the RE Process Modeling}

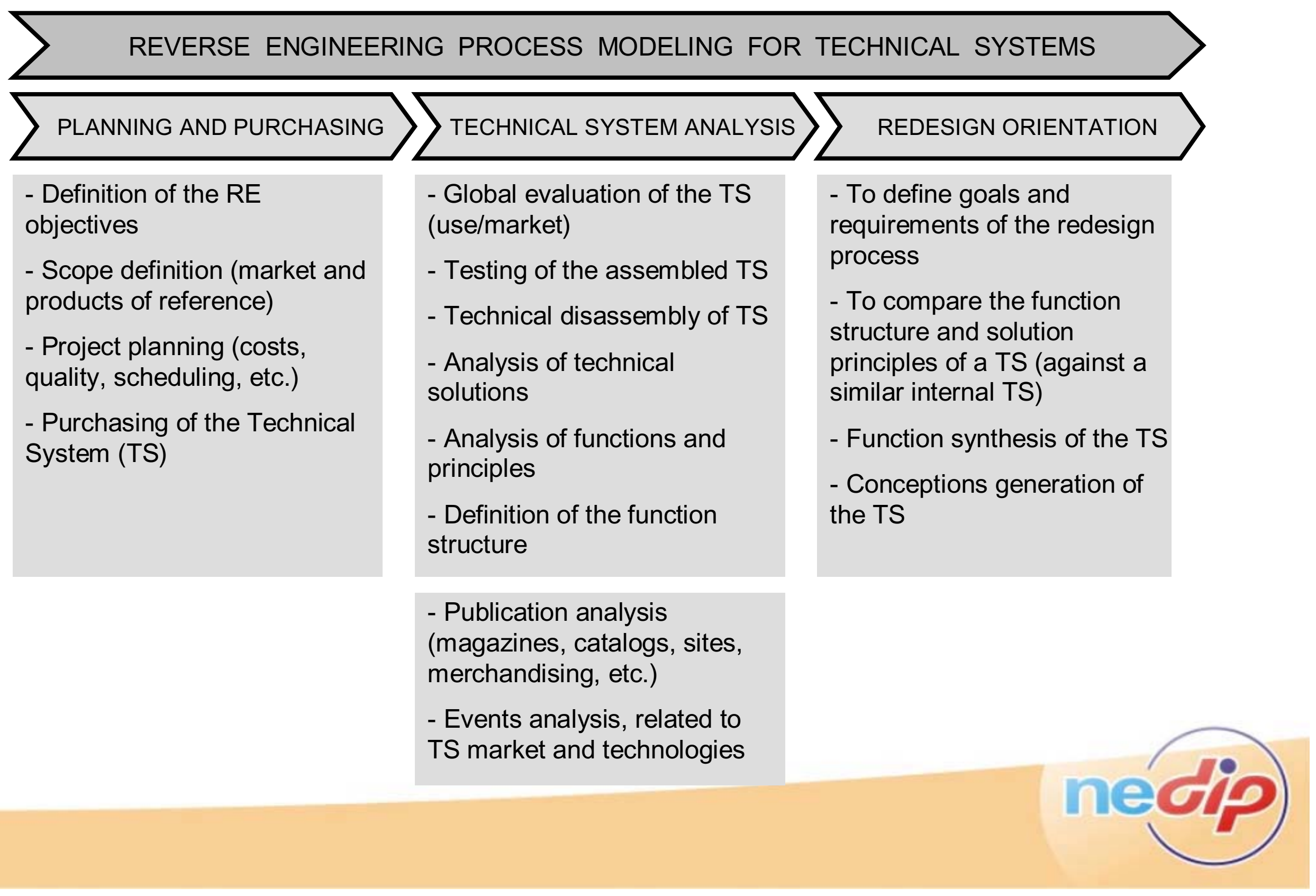




\section{Proposal for the RE Process Modeling}

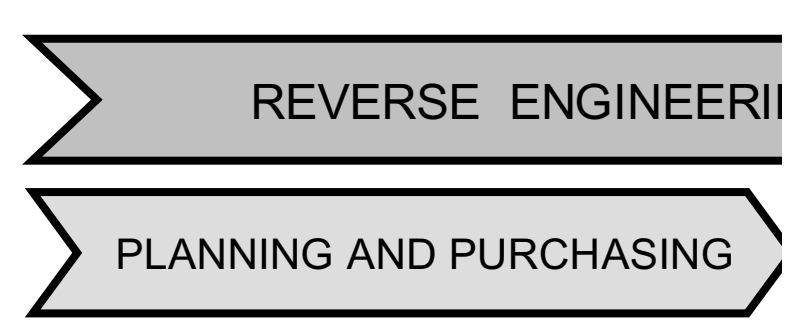

- Definition of the RE objectives

- Scope definition (market and products of reference)

- Project planning (costs, quality, scheduling, etc.)

- Purchasing of the Technical System (TS)
- GOAL: to plan the activities of the RE process, and to orientate the designers to purchase the right TS to be analyzed

- RESULTS: the project plan of the RE process and the TS purchasing 


\section{Proposal for the RE Process Modeling}

Planning and Purchasing Map Price $x$ Value
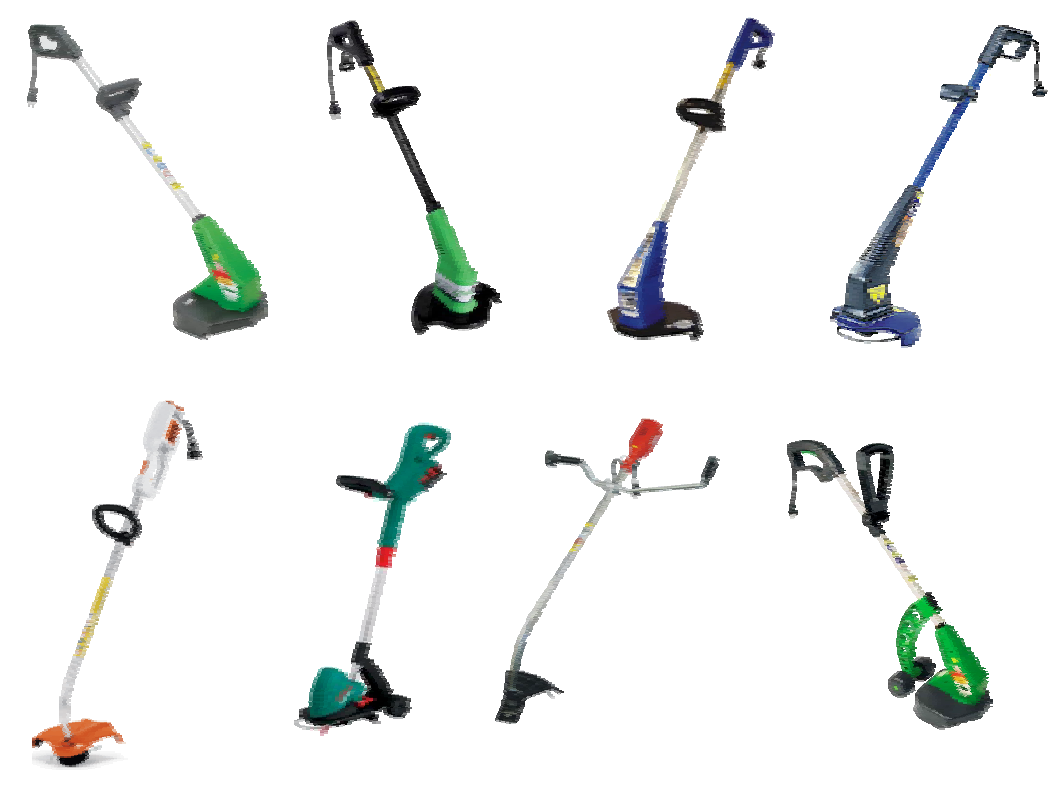

PQ
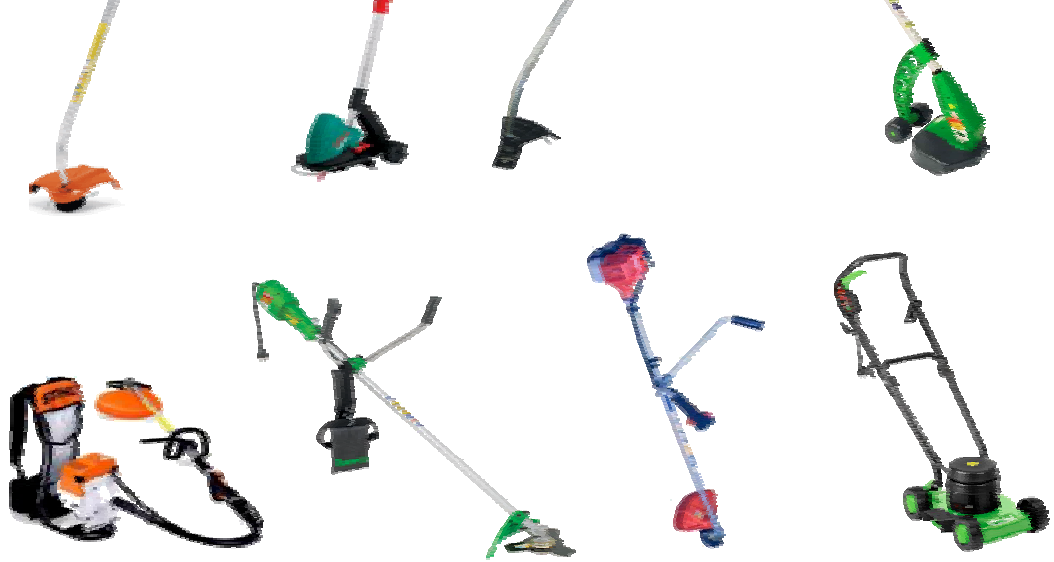
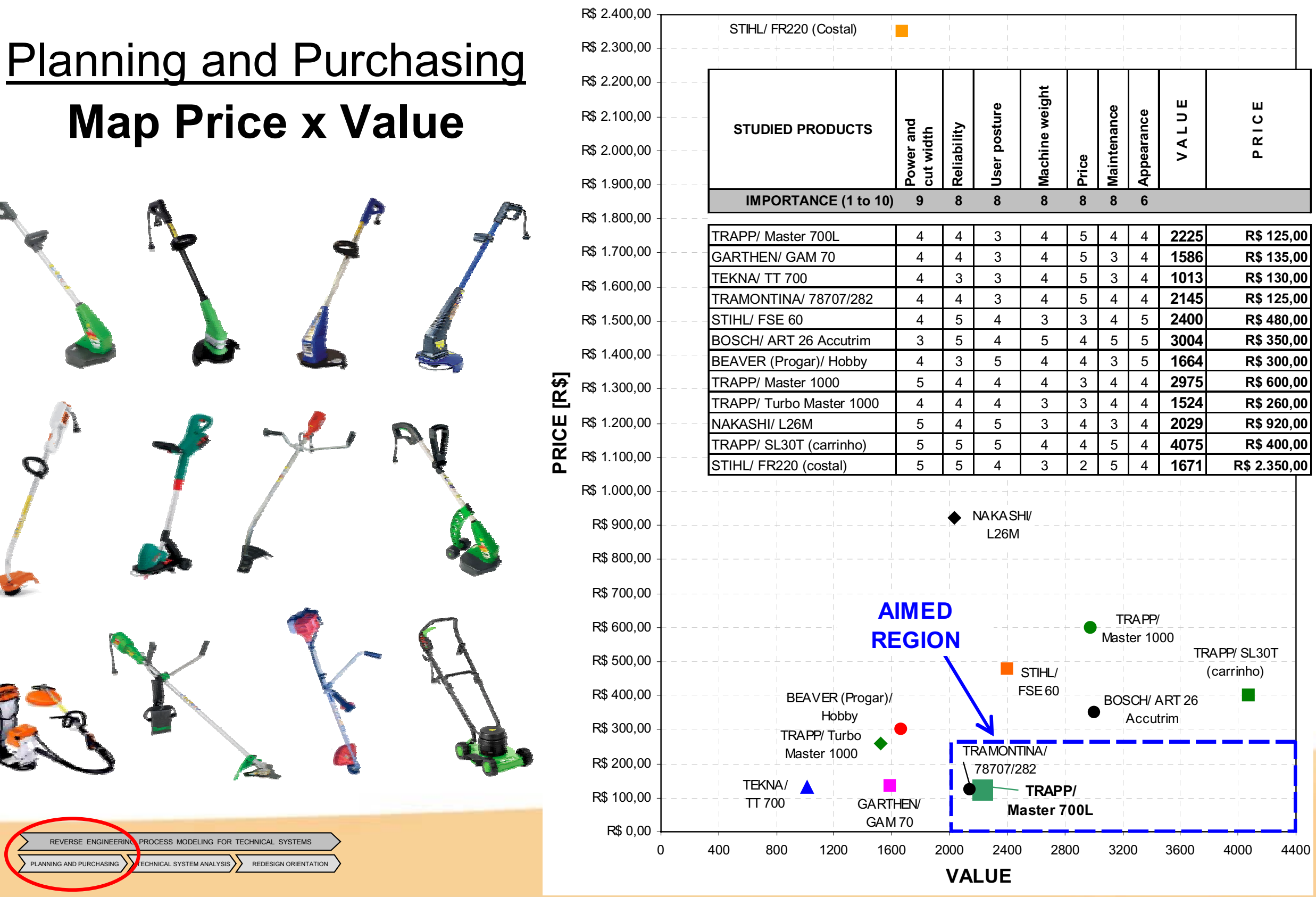


\section{Proposal for the RE Process Modeling}

VG PROCESS MODELING FOR

TECHNICAL SYSTEM ANALYSIS

- Global evaluation of the TS (use/market)

- Testing of the assembled TS

- Technical disassembly of TS

- Analysis of technical solutions

- Analysis of functions and principles

- Definition of the function structure

- Publication analysis (magazines, catalogs, sites, merchandising, etc.)

- Events analysis, related to TS market and technologies
- GOAL: to obtain information which can be used in future designs and redesigns

- RESULTS: a list of components and materials; TS description; information on technical performance; and the functions identification 


\section{Proposal for the RE Process Modeling}

VG PROCESS MODELING FOR

> TECHNICAL SYSTEM ANALYSIS

- Global evaluation of the TS (use/market)

- Testing of the assembled TS

- Technical disassembly of TS

- Analysis of technical solutions

- Analysis of functions and principles

- Definition of the function structure

- Publication analysis (magazines, catalogs, sites, merchandising, etc.)

- Events analysis, related to TS market and technologies

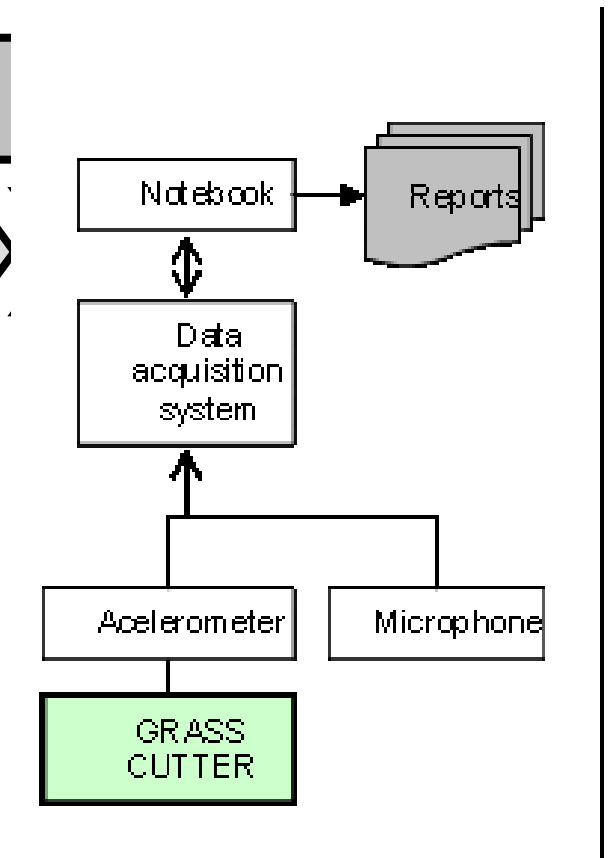

a) Data acquisition
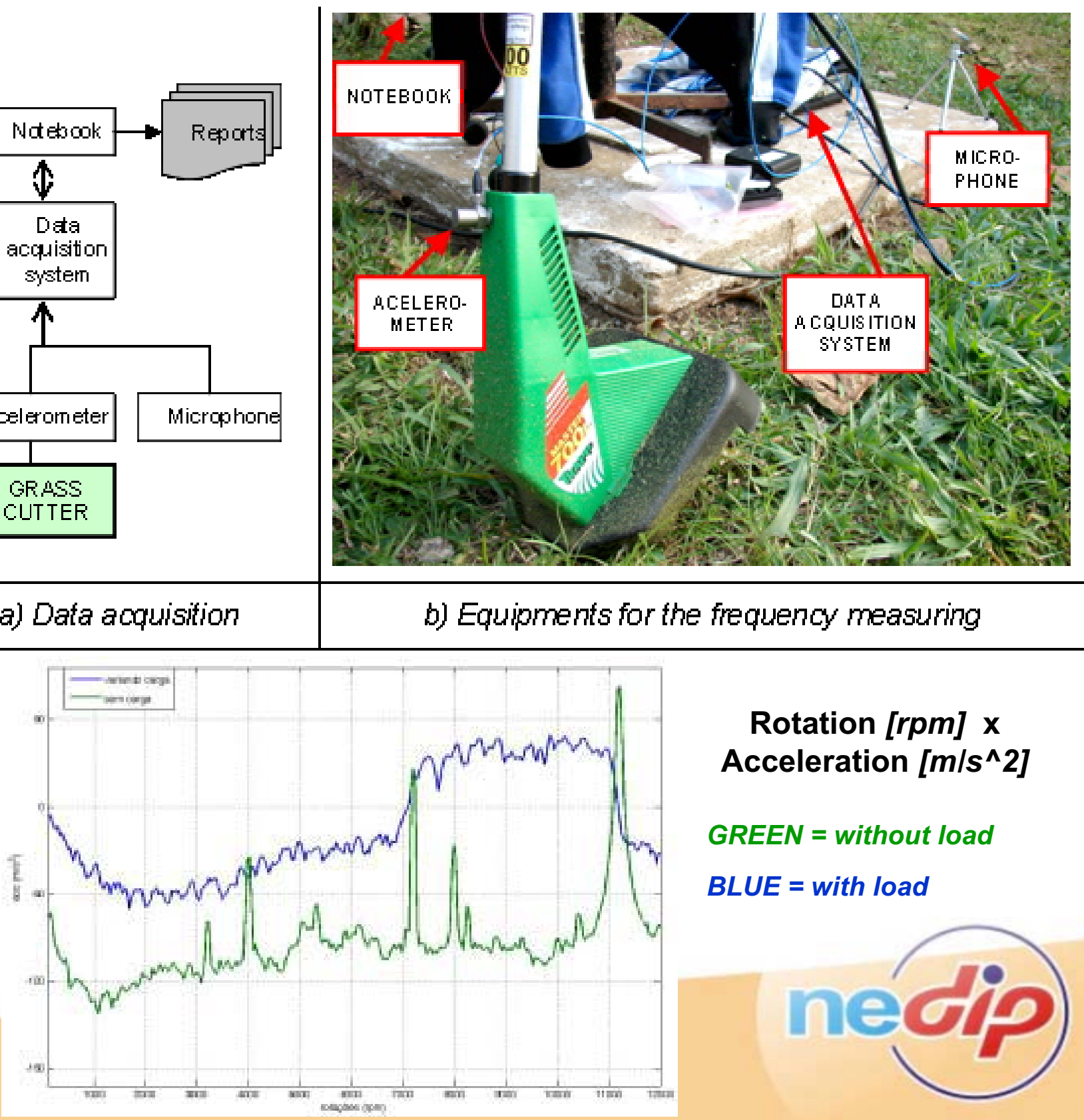

Rotation [rpm] $\mathrm{x}$ Acceleration [m/s^ 2 ]

GREEN = without load

BLUE = with load

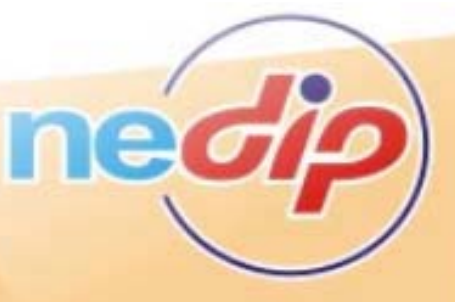




\section{Proposal for the RE Process Modeling}

VG PROCESS MODELING FOR

> TECHNICAL SYSTEM ANALYSIS

- Global evaluation of the TS (use/market)

- Testing of the assembled TS

- Technical disassembly of TS

- Analysis of technical solutions

- Analysis of functions and principles

- Definition of the function structure

- Publication analysis (magazines, catalogs, sites, merchandising, etc.)

- Events analysis, related to TS market and technologies

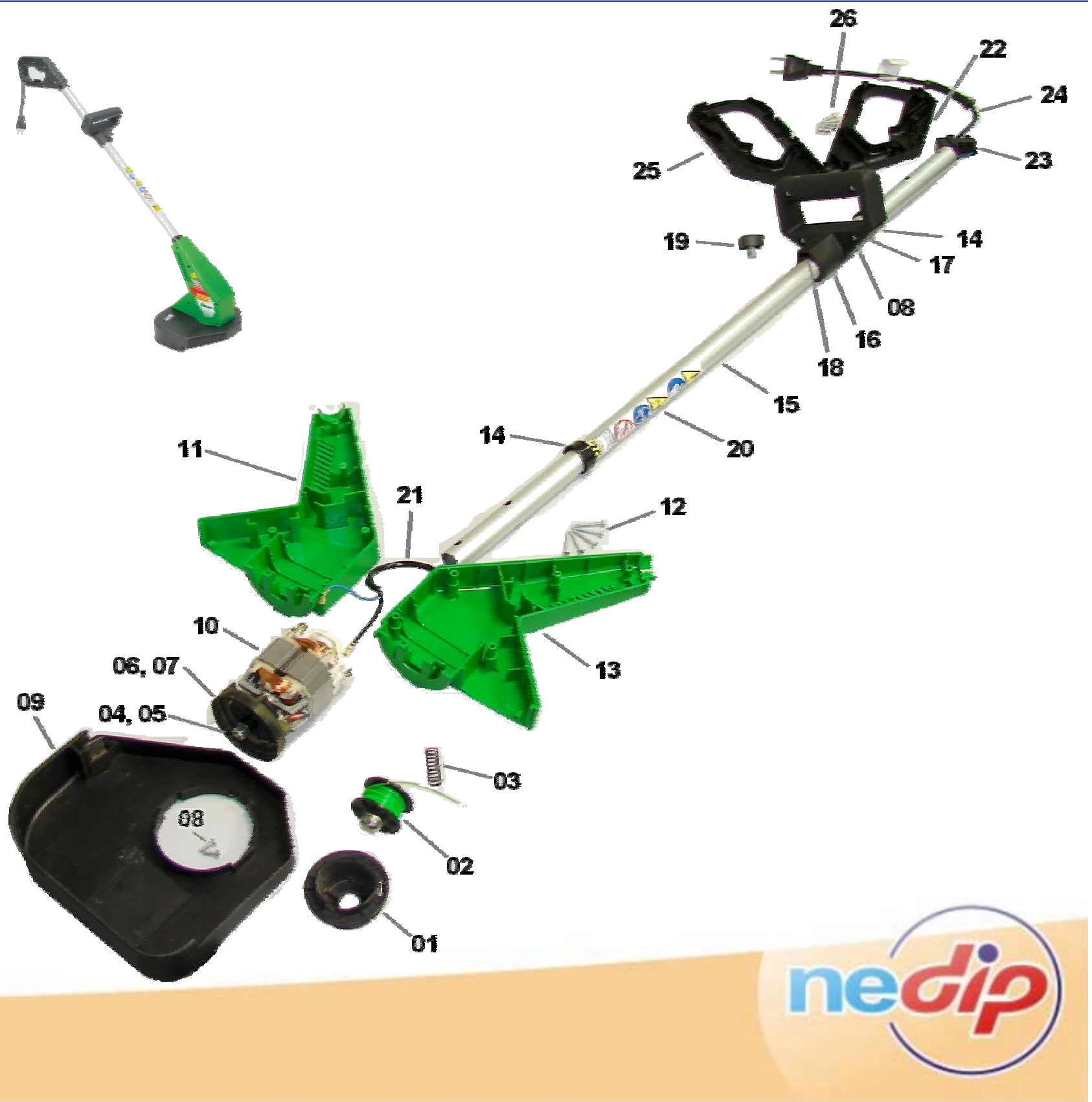




\section{Proposal for the RE Process Modeling}

VG PROCESS MODELING FOR

>TECHNICAL SYSTEM ANALYSIS

- Global evaluation of the TS (use/market)

- Testing of the assembled TS

- Technical disassembly of TS

- Analysis of technical solutions

- Analysis of functions and principles

- Definition of the function structure

- Publication analysis (magazines, catalogs, sites, merchandising, etc.)

- Events analysis, related to TS market and technologies
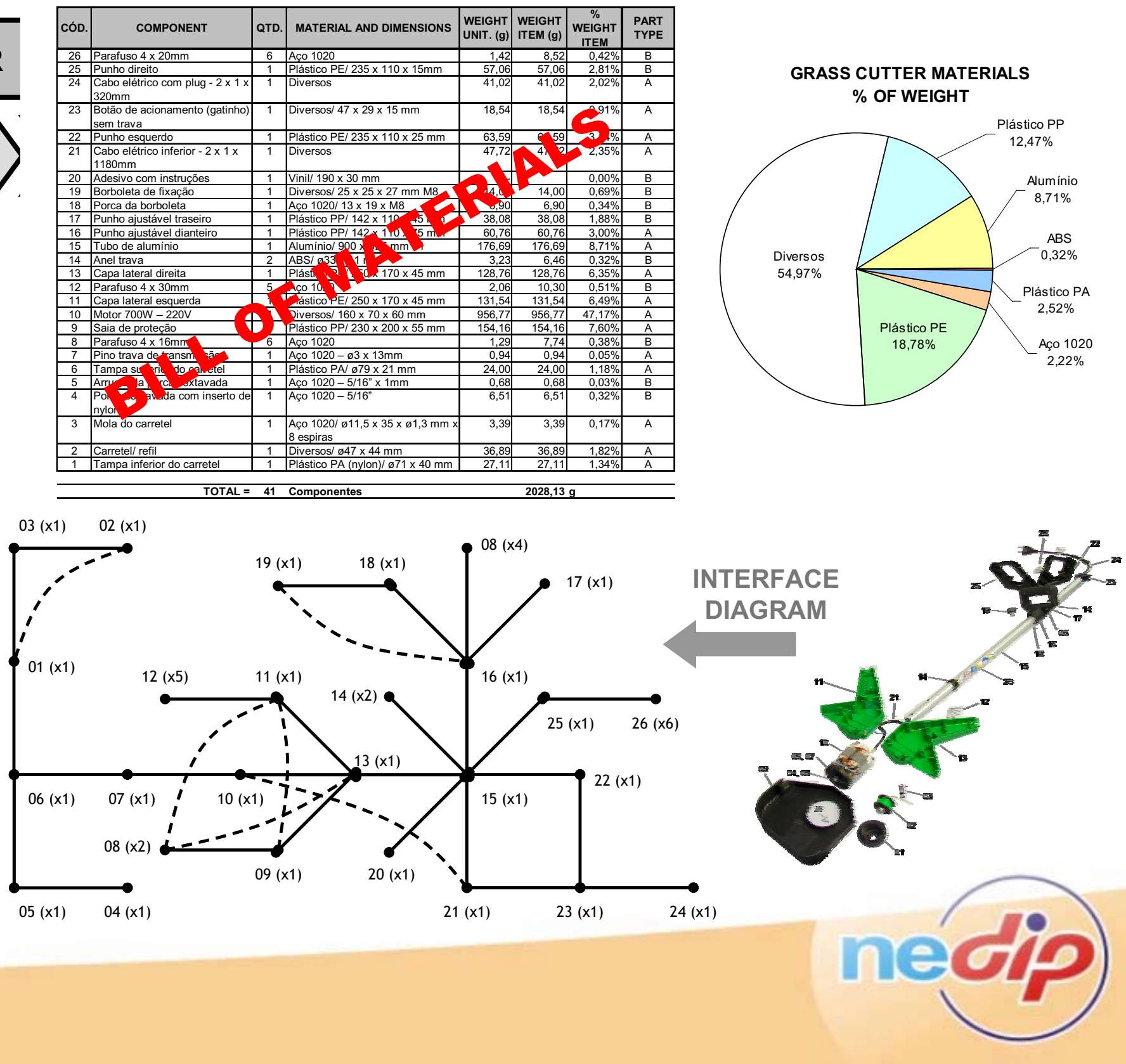


\section{Proposal for the RE Process Modeling}

VG PROCESS MODELING FOR

> TECHNICAL SYSTEM ANALYSIS

- Global evaluation of the TS (use/market)

- Testing of the assembled TS

- Technical disassembly of TS

- Analysis of technical solutions

- Analysis of functions and principles

- Definition of the function structure

- Publication analysis (magazines, catalogs, sites, merchandising, etc.)

- Events analysis, related to TS market and technologies

\section{FUNCTION STRUCTURE:}

USING SOP (SUBTRACT AND OPERATE PROCEDURE) AND

FAST (FUNCTION ANALYSIS AND SYNTHESIS TECHNIQUE)
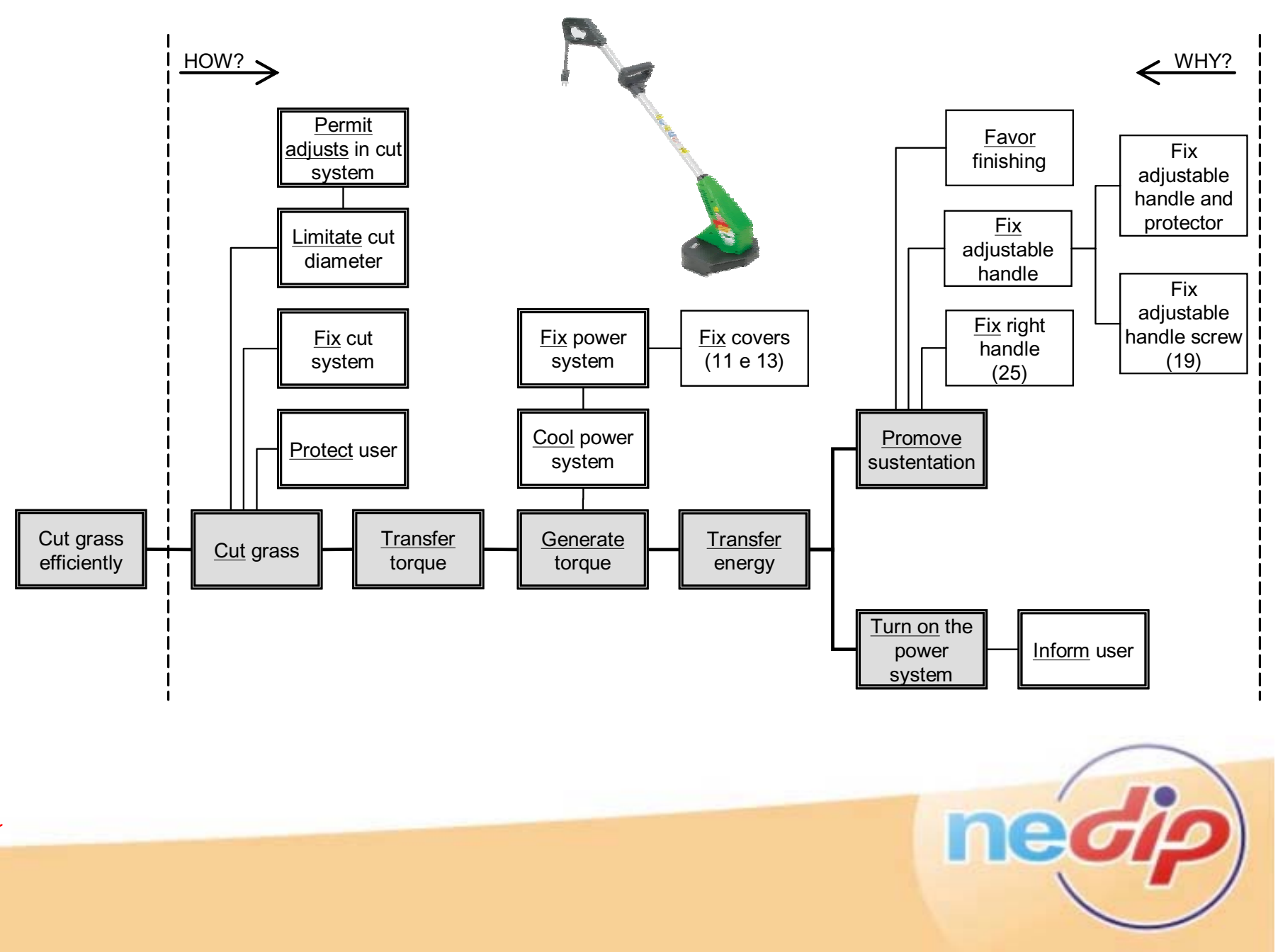


\section{Proposal for the RE Process Modeling}

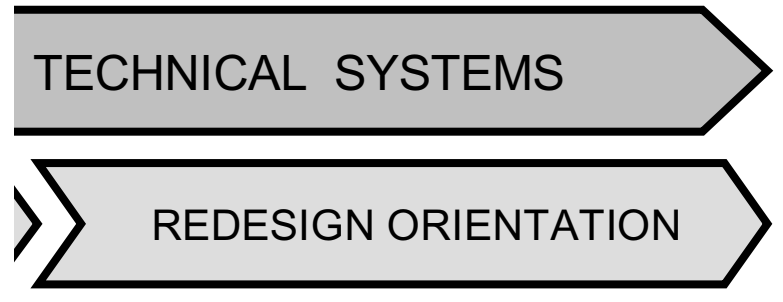

- To define goals and requirements of the redesign process

- To compare the function structure and solution principles of a TS (against a similar internal TS)

- Function synthesis of the TS

- Conceptions generation of the TS
- GOAL: the goals and requirements of the TS redesign are defined, indicating which subsystems should be optimized

- RESULTS: the redesign of goals, a comparative analysis of the function structures, the optimized function structure and the attributes of the new versions of the TS conceptions 


\section{Proposal for the RE Process Modeling}

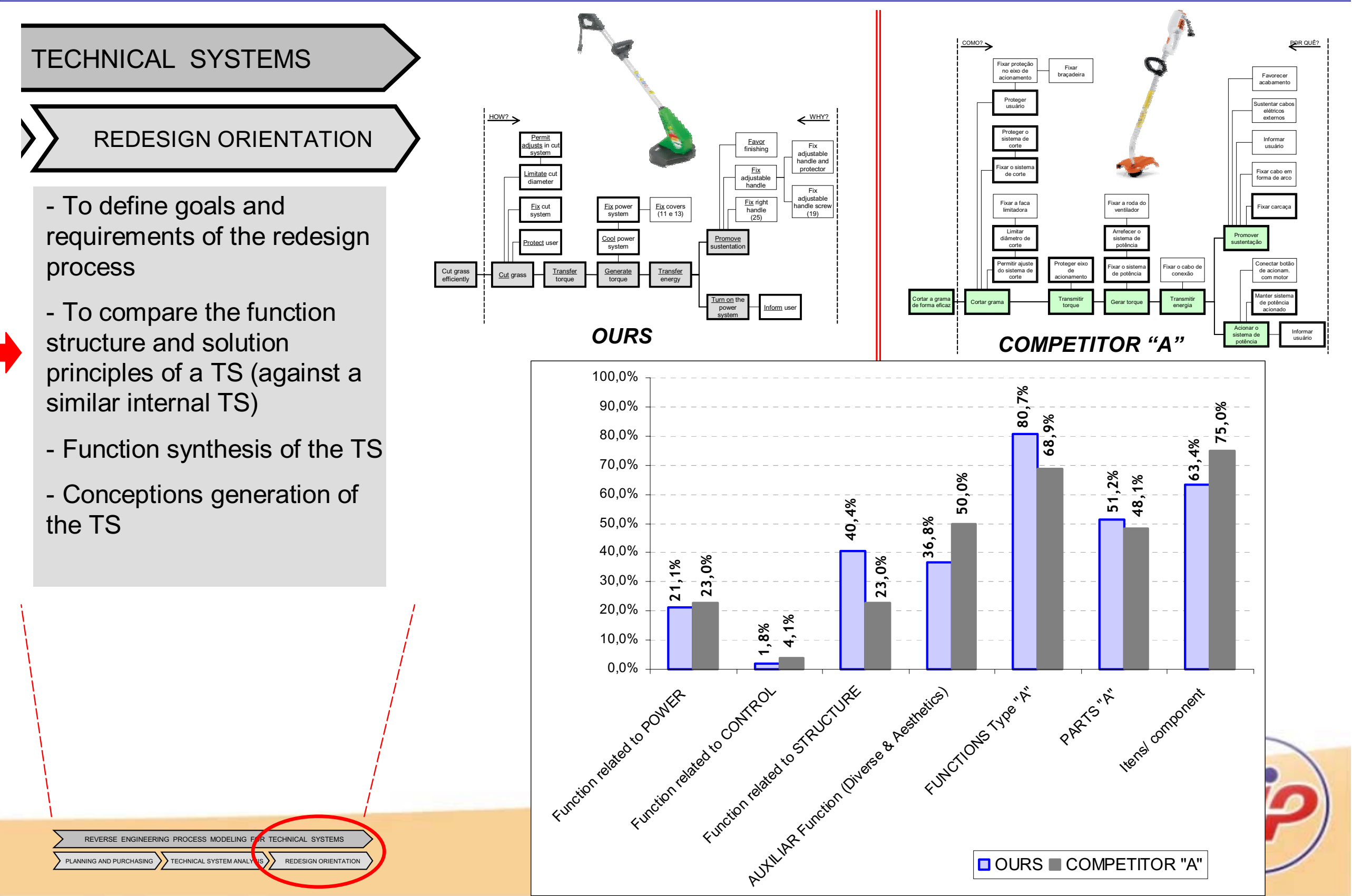




\section{Proposal for the RE Process Modeling}

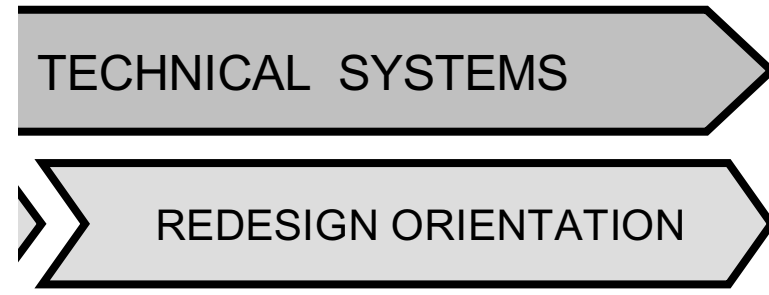

- To define goals and requirements of the redesign process

- To compare the function structure and solution principles of a TS (against a similar internal TS)

- Function synthesis of the TS - Conceptions generation of the TS

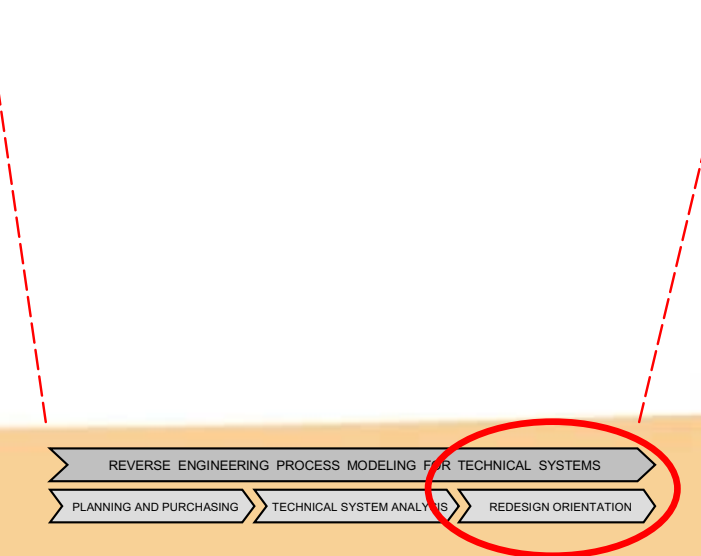

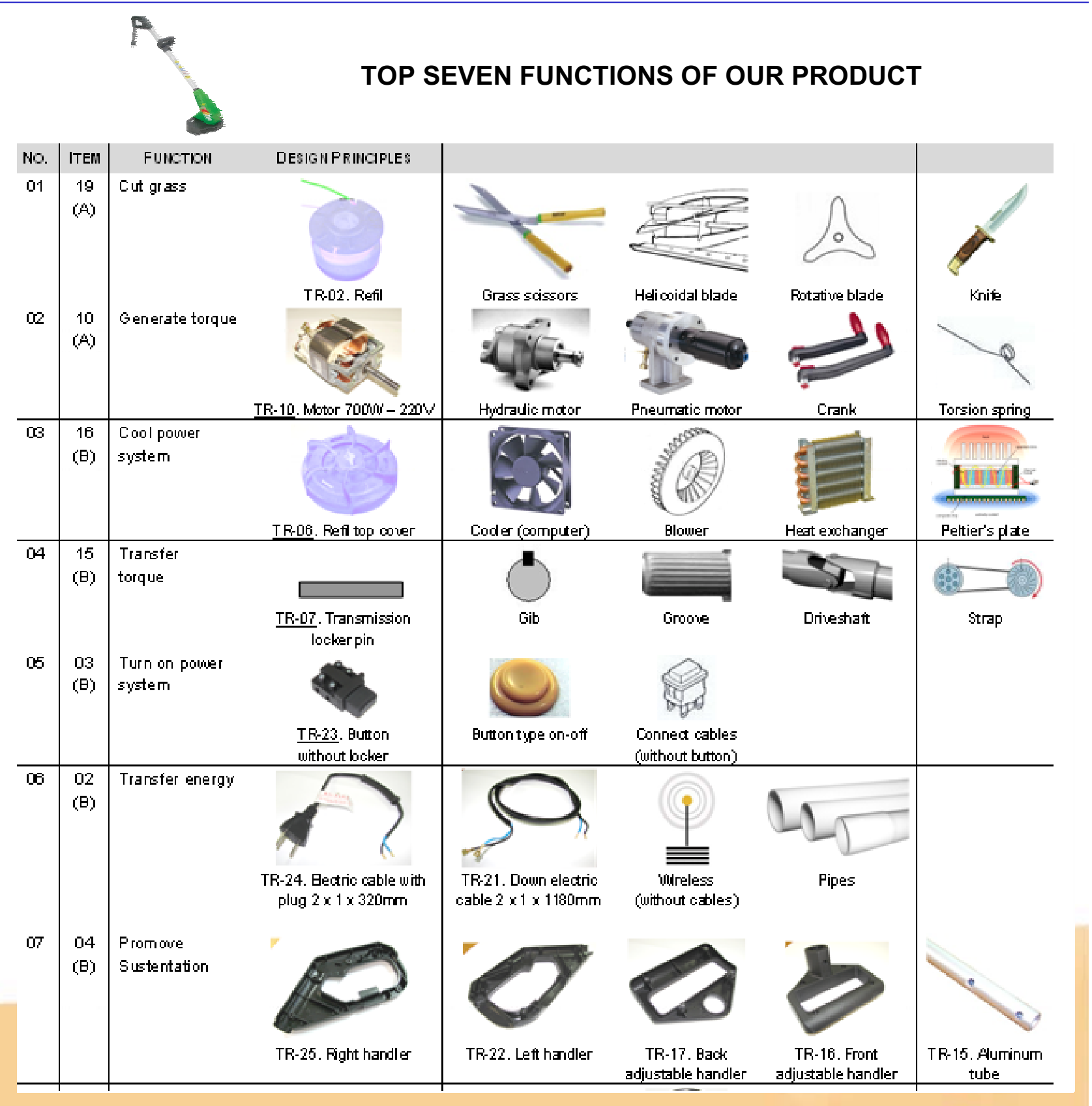




\section{Guidelines for the RE Model}




\section{Guidelines for the RE Model}

- To study processes of functional modeling, in order to define the information structure needed to describe the TS functions, considering the function deployment levels and the right technical language

- To develop a method for the comparative analysis of TS function structures, considering the functions of each subsystem, the interaction among functions, types of flows, types of transformations, etc.

- To develop a database, who will permit the comparison of similar functions, as well as the registration of functions and solution principles from many areas - mechanical, electrical, optical, bionic (analogy with nature), and others - to satisfy the design needs 


\section{Final Considerations}




\section{Final considerations}

- The RE process formalizing supports the identification of TS functions and solution principles

- A comparative analysis between the studied TS and an internal TS can favor an improvement in the TS

- By utilizing the RE process as a source of knowledge for innovations in TS, companies can develop TS solutions in a faster way and with less uncertainties, in relation to a project without comparison parameters

- However, our methodology is currently being developed. For this reason, practical results in companies have still not been obtained, but they will be reported before the end of this year. 


\section{Contacts}

Guidelines for Reverse Engineering Process Modeling of Technical Systems

Ivo Rodrigues Montanha Junior, M.Eng. (M.Sc.)

IVOJR@nedip.ufsc.br

André Ogliari, Dr.Eng.

OGLIARI@emc.ufsc.br

Nelson Back, Ph.D

BACK@emc.ufsc.br

www.nedip.ufsc.br 